\title{
Improve your Overall Health...Eat Right!!
}

\section{Aradhana Dixit*}

Department of Food and Nutrition, India

*Corresponding Author: Aradhana Dixit, Department of Food and Nutrition, India.

Received: August 27, 2019; Published: October 10, 2019

DOI: $10.31080 /$ ASNH.2019.03.0494

A person is said to be healthy if he/she is physically, socially and has mental well being... is a popular definition...but moreover we can add that a person is nutritionally fit too.

A well nutritionally balanced person can be judged as per following criteria's:

- $\quad$ Bounce in hair

- Healthy glowing skin

- Is alert

- Shinning skin

- Appropriate height and weight

It is said "healthy mind lives in healthy body". Nutrition is related to overall fitness

- $\quad$ Physical fitness: If there is proper growth and development at all stages of life person is said to be nutritionally fit.

For proper growth eat

Macronutrients in right proportion.

Mental fitness: A person is alert and active. He is having good sleep, is attentive and concentrates well is said to be nutritionally fit. For this:

- $\quad$ Take caffeine in appropriate amount and

- Limit alcohols

Nutritional fitness: Carbs and proteins together keeps you going and keep energy levels high.

Foods like

- Bananas

- Sweet potatoes

- $\quad$ Eggs and

- Water are some that helps you achieve energy levels.

Lack of vitamin B12, iron or vitamin D can make you feel tiered...take supplements like Coq10 and B complex to keep your energy levels boosted.

Vitamin B12 helps to make RBCs which transport oxygen throughout the body. Eat liver, eggs, fortified cereals to take care of.
In India there is deficiency of micronutrients like iodine, iron and vitamin D generally. Protein energy malnutrition is also prevalent.

\section{Social well being and nutrition}

It is important to have one meal at least at one dinning table by family...eating fruits and vegetables and freshly prepared served food is good for health.

Eat right!!! And improve your overall health.

Volume 3 Issue 11 November 2019

(C) All rights are reserved by Aradhana Dixit. 